\title{
Business classification of Power Grid Enterprises in the development environment of Energy Internet
}

\author{
Xin $\mathrm{Li}^{1 *}$, Yuan Zhang ${ }^{2}$ \\ ${ }^{1}$ Country State Grid Energy Research Institute Co., Ltd., Beijing, China \\ ${ }^{2}$ Country State Grid Energy Research Institute Co., Ltd., Beijing, China
}

\begin{abstract}
Energy Internet is centered on electricity, based on a strong smart grid, and deeply integrates advanced information and communication technology, control technology and advanced energy technology to support the clean and low-carbon transformation of energy and electric power, comprehensive utilization efficiency optimization of energy, and the access of flexible and convenient multiple entities, which is a smart energy system with the characteristics of green safety, ubiquitous interconnection, efficient interaction, and intelligent openness. This article focuses on the impact of the development of the Energy Internet on power grid companies and the main business of power grid companies in the future development environment of the Energy Internet, providing references for the transformation and development of power grid companies.
\end{abstract}

\section{The first section in your paperThe impact of the development of the Energy Internet on power grid companies}

Energy Internet realizes the deep integration of Internet innovation elements and traditional energy industry. The integration of Internet technology and the penetration of Internet spirit have also injected new power elements into the energy industry. The development of the energy Internet has brought major changes to the production, transmission and consumption of energy systems.

\subsection{Energy production is more low-carbon}

Building a clean, low-carbon, safe and efficient newgeneration energy system and realizing energy transition are the core goals of the new round of energy revolution [1]. With the increasing impact of global warming and environmental degradation, large-scale development and wide-area deployment of clean energy have become the consensus of all countries, which is the only way to promote world energy reform. Replacing fossil energy with renewable energy on the power generation side is a more fundamental transformation goal for achieving a green economy, and emission reduction commitments have made China one of the main drivers of the global "renewable energy substitution"

\subsection{Energy transmission is more intelligent}

With the application of advanced power electronic technology and information and communication technology, the flexibility and reliability of energy transmission will be further improved, making energy transmission more intelligent and automated ${ }^{[2]}$. Efficient energy transmission requires timely absorption of renewable energy with intermittent, sudden and other characteristics, as well as monitoring and other computing equipment that control energy flow and adjust energy types to meet consumer demand. The integration of advanced information and communication technologies and the power sector will have an impact on energy transmission in terms of technology, form, and function.

\subsection{Energy consumption is more diverse}

The energy Internet allows consumers to fully meet their individual needs. With the development of the energy Internet, consumer needs tend to be diversified, and the interaction with grid companies will be further strengthened. On the energy consumption side, the changes in the focus of energy consumers are mainly as follows:

Energy consumers want products and services to become simpler. Fast, simple, and easy services have become the most important requirements of global energy consumers for energy companies. Energy consumers want a seamless user experience, including the same service experience in different channels, easy

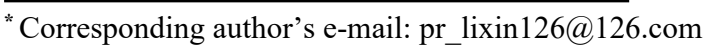


transaction processes, and convenience in different channels Switch. Consumers expect energy companies to provide personalized services based on user insights.

From a global perspective, the sharing of personal information and the advancement of big data processing technology have promoted the development of personalized service models, and consumers have higher and higher expectations for personalized services. Personalized services based on user behavior prediction are becoming more and more important. At the same time, the security of related data and the protection of user privacy have become the focus of consumers' concerns. To make energy consumption meaningful, "electricity" is not only "electricity", but also represents values. From a global perspective, "value beyond commodities" has become the focus of consumers' energy consumption. Consumers pay more attention to saving energy consumption expenditures, and are more interested in energy-saving products and energy products and services with renewable energy subsidies.

Information sharing and resource sharing have become a trend. From a global perspective, consumers' information sharing and resource sharing give users greater bargaining power and enable them to enjoy services without purchasing assets.

\subsection{Changes in the development model of power grid enterprises}

Energy Internet is a new form of energy industry development that deeply integrates the Internet with energy production, transmission, storage, consumption and energy markets. It is a comprehensive upgrade of the traditional power grid and will affect the development concept, corporate functions, technical characteristics, and business of grid companies. The scope, development model and other aspects have brought about comprehensive improvements and changes ${ }^{[3][4]}$.

In terms of development concept, it is changing to openness, interaction and sharing. Compared with the relatively closed development concept of traditional power grids, grid companies in the future will adopt a more open attitude to serve the diverse needs of users, promote market opening, and create a win-win ecosystem.

In terms of corporate functions, it has shifted from traditional grid business to a more comprehensive platform ecological business. In the future, the function of power grid enterprises will promote the creation of an efficient energy market through mechanism and format innovation.

In terms of technical characteristics, the transformation from traditional large-scale grid technology to strong smart grid and Internet of Things technology. With the high proportion of new energy sources, the widespread use of a large number of power electronic equipment, the increase in the scale of $\mathrm{AC}$ and DC hybrid power grids, and the application of information technology such as the "big cloud and mobile smart chain", the physical form and operation mode of the power grid will fundamentally change.

In terms of business scope, it has transformed from a single power supply business to multiple businesses such as integrated energy services and value-added services. In the future, the business scope of power grid companies will focus on user needs to develop integrated energy services such as multi-energy complementation, energy-saving transformation, equipment operation and maintenance, water, electricity and heating, as well as platform services such as Internet of Vehicles and energy storage cloud network. At the same time, develop valueadded derivative services such as big data credit investigation and advertising.

In terms of the development model, it has shifted from a power supply company to an energy ecological core company. In the future, power grid companies will focus on energy supply, gather energy producers, transmitters, consumers, equipment vendors, service providers and other diversified entities to create an energy Internet ecosystem of co-construction, governance and sharing.

\section{Business classification of grid enterprises}

From the perspective of conforming to the integration trend of the energy revolution and the digital revolution and the entire industry chain, power grid companies rely on grid operation as their main business, and new businesses that can be developed in the future are generally concentrated in the three major areas of industrial services, consumer services and asset operations. 


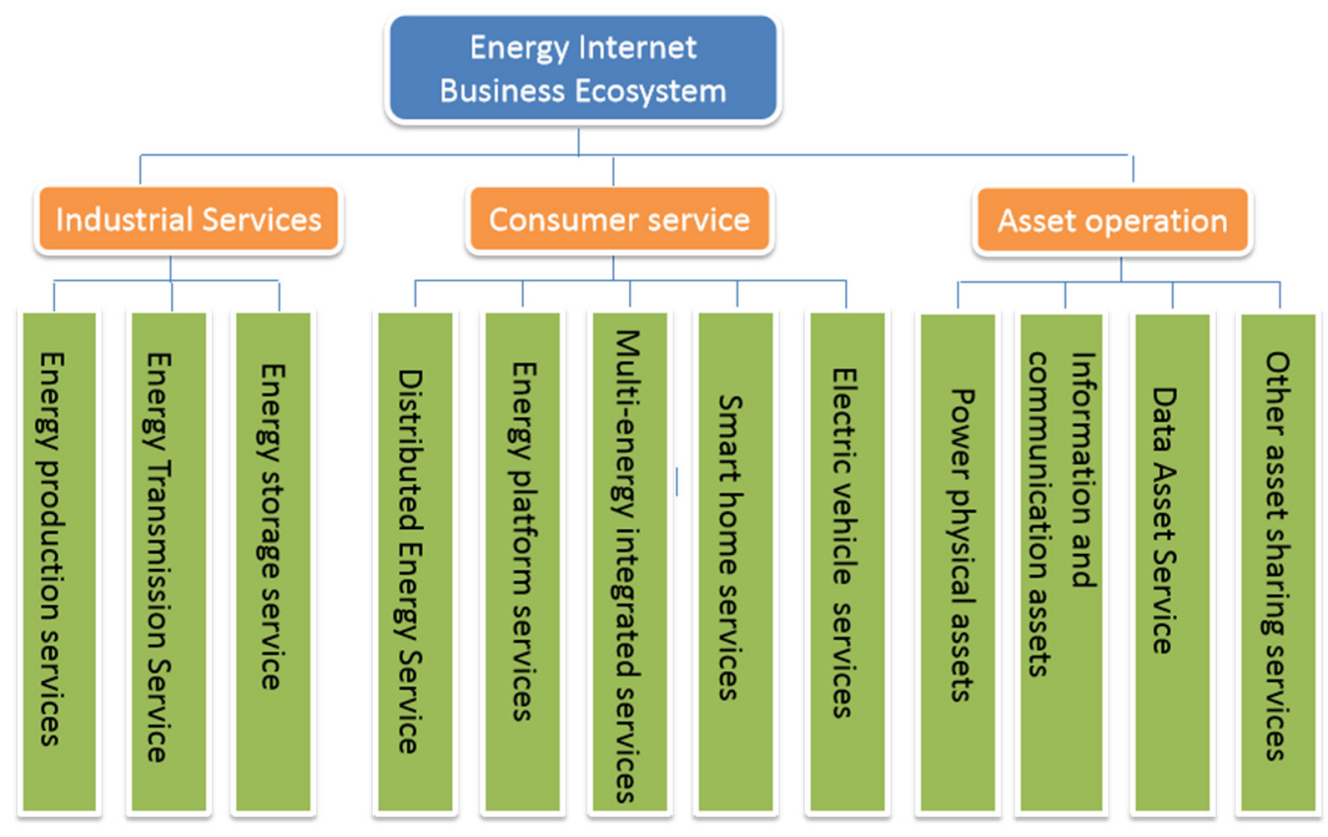

Fig 1 Energy Internet Business Classification

\section{Various business sub-ecologies of grid companies}

\subsection{A subsection Energy Industry Service Ecosystem}

The energy industry service business provides platforms and data services based on technologies such as the Internet of Things, the Internet, and big data for industrial links such as energy and power production, transmission, and storage. From the perspective of the source-network-storage industry chain, energy industry services include three types of service businesses: energy production, energy transmission and energy storage ${ }^{[5]}$.

The new energy big data service is mainly to construct and operate a new energy big data service platform to promote the development of the new energy industry. The intelligent manufacturing service of advanced components is mainly to carry out data analysis of the operation of energy Internet equipment, and serve the development of the intelligent manufacturing industry of advanced components of power electronics. Power equipment monitoring and operation services are mainly to carry out the digital operation of power equipment monitoring, promote the full perception of equipment status in all links of energy transmission, and provide high-quality intelligent operation inspection services. The energy storage cloud platform service is mainly to build and operate an energy storage cloud platform, aggregate various energy storage resources, and help the construction of the energy Internet

\subsection{Energy consumption service ecosystem}

The consumer service business provides comprehensive services such as energy, platform and data for individuals, households, industrial and commercial and government users in the energy and power consumption link. From the perspective of the end-user market of energy consumption, grid companies can develop energy consumption service businesses, including distributed energy services, energy platform services, multi-energy integrated services, smart home services, electric vehicle charging services, etc., and continue to improve user stickiness and various services. Class service level.

Smart city energy management platform services are mainly to grasp the customized top-level design and digital transformation and upgrading trend of smart city construction, build a smart city energy management platform, and deeply participate in the construction and operation of smart energy systems. Smart home is mainly to build the Internet of Things for smart homes, based on the home energy management business, and expand the development of home consumption e-commerce and advertising businesses. Grid companies can focus on household consumer groups, upgrade terminal sensing devices such as smart meters, help users understand household energy consumption behavior, and create a smart home ubiquitous Internet of Things with electric energy flow and information flow as the main carrier ${ }^{[6]}$. The integrated energy service business is mainly to develop integrated energy services that match market needs in small areas such as industrial parks, communities, and buildings. The smart car networking business is mainly to build and operate a smart car networking ecosystem based on the organic integration of information networks, transportation networks and energy networks, to build itself into a sharing platform for smart transportation and smart energy, and to give full play to the strategic value of platform interconnection

\subsection{Asset operation business ecosystem}

The focus of asset operation business is to tap the value of internal resources, provide external shared services 
through a reasonable business model, and realize the realization of asset value. From the perspective of the physical characteristics of the network, company assets under the Energy Internet can be deconstructed into three categories: energy allocation network, information communication network, and data assets.

The energy allocation network is the basic platform for the power grid to realize the allocation of energy resources. It includes not only the physical power infrastructure, but also various energy infrastructures for multi-energy conversion and access. The information communication network is composed of an access network, a transmission network, a data network and a satellite network, and includes infrastructure such as data collection, transmission, storage, analysis, and utilization. As a new means of production, data assets include massive data such as power generation, electricity consumption, economy, population, weather, and policies, covering economic regions, administrative regions, industries, industries, and residents.

\section{Conclusion}

In order to accelerate the development of new businesses as soon as possible, grid companies should focus on supporting technology, supporting facilities, research and consulting, etc.

First, accelerate the development of business model research and consultation to have a clearer understanding of future development trends and prospects of various businesses, and lay a theoretical foundation for the subsequent development of new businesses. Second, accelerate the layout and construction of supporting facilities, focusing on strengthening the construction of various infrastructures such as smart grids, smart terminal sensing equipment, wireless + wired communication facilities, big data centers, and cloud platforms. Third, explore the platform business model and platform construction, focusing on the initial research and exploration of the connotation of the platform model, typical models, platform function design and platform construction

\section{Acknowledgments}

This paper was sponsored by the project "Research on key technologies for the development of State Grid Corporation's integrated energy service platform for ubiquitous power Internet" of Country State Grid Energy Research Institute

\section{References}

1. Tang Guangfu. Energy Internet supports the energy transition[J]. Power equipment management (EPEM), 2020.2:25-28

2. Zeng Ming.Two key problems during China's energy sector transformation towards clean energy [N]. State Grid News,2014-09-26

3. Ma Zhao,Zhou Xiaoxin,Shang Yuwei,Form and development trend of future distribution system[J]. Proceedings of the CSEE, 2015,35(6):1289-1298.

4. Yang Fang,Bai Cuifen,Zhang Yibin.Research on the value and implementation framework of energy internet[J]. Proceedings of the CSEE, 2015, 35(14): 3495-3502.

5. HUANG Renle, PU Tianjiao, LIU Kewen. Design of hierarchy and functions of regional energy internet and its demonstration applications[J]. Automation of Electric Power Systems, 2015, 39(9):26-33.

6. Tian Shiming, Luan Wenpeng, Zhang Dongxia, etc. Energy Internet technology form and key technology $[\mathrm{J}]$ Proceedings of the Chinese Society for Electrical Engineering, 2015, 35(14): 3482-3494 